University of Louisville

ThinkIR: The University of Louisville's Institutional Repository

\title{
$5-2013$
}

\section{Subjective depression and thought disorder in schizophrenia : are they related?}

Ariel Briggs

University of Louisville

Follow this and additional works at: https://ir.library.louisville.edu/honors

Part of the Psychology Commons

\section{Recommended Citation}

Briggs, Ariel, "Subjective depression and thought disorder in schizophrenia : are they related?" (2013). College of Arts \& Sciences Senior Honors Theses. Paper 54.

http://doi.org/10.18297/honors/54

This Senior Honors Thesis is brought to you for free and open access by the College of Arts \& Sciences at ThinkIR: The University of Louisville's Institutional Repository. It has been accepted for inclusion in College of Arts \& Sciences Senior Honors Theses by an authorized administrator of ThinkIR: The University of Louisville's Institutional Repository. This title appears here courtesy of the author, who has retained all other copyrights. For more information, please contact thinkir@louisville.edu. 
Depression and Thought Disorder in Schizophrenia

Subjective Depression and Thought Disorder in Schizophrenia: Are They Related?

By

\section{Ariel Briggs}

Submitted in partial fulfillment of the requirements

for Graduation summa cum laude

and

for Graduation with Honors from the Department of Psychological and Brain Sciences

University of Louisville

May 2013 


\section{Subjective Depression and Thought Disorder in Schizophrenia: Are They Related?}

\section{Affect in Schizophrenia}

The phenomenon of affective symptoms in schizophrenia is one that is poorly understood. This is in part due to the complex relationship between affective and psychotic symptoms seen in schizophrenia, schizoaffective disorder, major depression, and bipolar disorder (Buckley, Miller, Lehrer, \& Castle, 2009). When strong affective symptoms are accompanied by psychotic symptoms, it often results in a diagnosis of unipolar depression or bipolar disorder. In contrast, the presence of psychotic symptoms with few affective symptoms often results in a diagnosis of schizophrenia (Van Os \& Kapur, 2009). Schizoaffective disorder appears to be an intermediate condition, or a mixture of an affective disorder and schizophrenia. In the Diagnostic and Statistical Manual of Mental Disorders, Text Revised version (DSM IV-TR; American Psychiatric Association [APA], 2000), psychotic disorders are classified by the presence or absence of affective symptoms. Yet even with this guide to diagnosing psychotic illnesses, sharp boundaries between them are unclear.

Andreasen (1989) explains how the current diagnosis has come to exclude affective symptoms. In the 1970s, cross-national studies showed that the diagnosis of schizophrenia was more broadly defined in the United States than in most other countries due to two conflicting schools of thought: one focusing on "associative loosening, affective blunting, ambivalence, and autism" (Andreasen 1989, p. 520) as the core components of schizophrenia, and the other focusing on psychosis at the core. Upon the observation that some schizophrenic patients responded better to drugs normally used to treat affective illnesses, it was later concluded that these patients had been misdiagnosed and were actually suffering from affective conditions. Subsequently, the criteria for the diagnosis of schizophrenia became narrower, and conditions 
with strong affective components became classified as affective illnesses (Andreasen, 1989). As a result, the role of affect in schizophrenia had been overlooked for many years.

Recently there has been an increase in the investigation of affect and emotion in schizophrenia. Whereas affect refers to a more general, average feeling over a longer period of time, emotion refers to an immediate response to a stimulus, and therefore is more variable from moment-to-moment. Although it was commonly believed that schizophrenic patients did not experience emotion, as they tend not to express it outwardly, they report experiencing emotions as strongly as healthy individuals. Furthermore, studies of physiological measures of emotion including skin conductance, facial muscle activity, and the startle response, have also confirmed that schizophrenic individuals experience emotion similarly to their healthy counterparts (Kring \& Caponigro, 2010). Studies such as these are important in correcting the outdated belief that individuals with schizophrenia do not experience emotions, and they provide a starting point for further investigation of the manifestation of and role of emotions and affect in this illness.

In the past decade, there has been an increase in research examining the role of depression in schizophrenia. It has been documented that depressive symptoms are often present in schizophrenia (Buckley, Miller, Lehrer, \& Castle, 2009; Lako et al., 2012; Van Os \& Kapur, 2009), yet the role of these symptoms is unclear. While it is possible that they may be part of the illness, it is also possible that patients may experience depression as a comorbid illness. Schizophrenia is a heterogeneous condition, with no two cases exactly alike. To further complicate the condition, one patient may experience different symptoms over time, and the interaction of various symptoms can lead to different outcomes (Buckley et al., 2009).

\section{Neurocognitive Functioning in Schizophrenia}


A more frequently studied aspect of schizophrenia is the neurocognitive deficits displayed by the majority of patients. Although each affected individual does not show impairment on every measure of neuropsychological function, Elvevag and Goldberg (2000) report that the four principal cognitive deficits of this illness are in attention, working memory, episodic memory, and semantic memory, and that the deficits in these domains are at the core of schizophrenia.

Individuals with schizophrenia have also been documented to perform poorly on tasks of executive functioning, which requires the use of skills such as focused attention, planning, and organization. Of the existing executive functioning tasks, the most commonly used to study deficits in this domain in schizophrenia is the Wisconsin Card Sort Test (WCST). Although impaired performance on the WCST is believed to represent frontal lobe lesions, the association between task performance and frontal lobe functioning is very weak, as there have been instances in which patients with severe frontal lesions have completed the task without demonstrating impairment (Laws, 1999).

Due to the heterogeneity of neurocognitive deficits displayed in schizophrenic patients, there have been some attempts to study the link between certain deficits and symptomology. Schizophrenia is often divided into two main subtypes: positive and negative. Positive symptomology represents an excess of what is seen in healthy individuals; hallucinations and delusions are two examples of positive symptom. Positive schizophrenia includes the following symptoms: hallucinations, delusions, positive thought disorder (thought disorder will be discussed later in the introduction), and bizarre and disorganized behavior. Conversely, negative symptomology represents an absence of what is seen in healthy individuals. Negative schizophrenia includes these symptoms: alogia (poverty of speech and poverty of content of 
speech), affective flattening, anhedonia-asociality, avolition-apathy, and attentional impairment (APA, 2000; National Institute of Mental Health [NIMH], 2009). However, many patients show a combination of these symptoms, a condition called mixed schizophrenia (Adreasen \& Olsen, 1982).

\section{Thought Disorder in Schizophrenia}

Another component of schizophrenia that has received substantial attention is thought disorder. Since the late nineteenth century, when Emil Kraepelin first described dementia praecox, thought disorder has been viewed as a central component of schizophrenia (Andreasen, 1982; Levy et al., 2010). Yet despite its prevalence in schizophrenia as well as other psychotic illnesses, the term thought disorder is not clearly defined, which has resulted is a non-uniform usage. One issue with the term is the broadness with which it is used. Thought disorder has been used to describe both disruptions in the content of thought, such as delusions, as well as in the form of thought, or thought processes. In this investigation, the term thought disorder is used to refer to formal thought disorder. A second issue has to do with the intimate relationships between thought, speech, and communication. While they are obviously intricately linked, they are not perfectly correlated with one another. Spoken or written language is necessary to convey thoughts, but language can also be used to distort or hide true thoughts. Because it is impossible to directly observe individuals' thought processes, it is necessary to rely upon spoken or written language to evaluate thought disorder (Andreasen, 1979a).

Formal thought disorder is often broken down into two broad categories: positive and negative, which can each be broken down further into subtypes (Andreasen, 1979b). Positive thought disorder includes the following subtypes: derailment, tangentiality, incoherence, illogicality, circumstantiality, pressure of speech, distractible speech, and clanging (Andreasen, 
1984). Negative thought disorder includes two subtypes: poverty of speech and poverty of content of speech (Andreasen, 1983). Definitions and examples of each subtype of thought disorder are provided in Table 1.

\section{The Relationship Between Depression and Neurocognitive Functioning in Schizophrenia}

In an effort to explore the little understood affective component of schizophrenia, Halari, Mehrotra, Sharma, and Kumari (2006) investigated the degree to which self-rated depression versus clinician-rated symptoms predicted schizophrenic patients' performance on a variety of neurocognitive tasks. Although they examined both self- and clinician-rated depression, which they found to be significantly and positively correlated, they used self-rated depression to predict performance on the neurocognitive tasks. They chose to use self-rated depressions because "altered subjective mood states ... are known to affect neurocognitive performance in healthy as well as psychiatric populations" (Halari et al., 2006, p. 752). Incidentally, they explored the possibility that subjective mood is a better predictor of performance on neurocognitive tasks than clinician-rated measures of depressive and psychotic symptoms. Halari et al. (2006) examined performance on neurocognitive tasks in nine domains: verbal ability, verbal memory, motor functioning, spatial motor functioning, spatial memory, executive functioning, attention, verbal working memory, and speed of information processing. They found that higher ratings of selfreported depression predicted poorer performance in the domains of attention, executive functioning, and verbal memory. In contrast, they found that clinician-rated symptoms only predicted impaired neurocognitive performance in one domain: motor functioning.

Although the significance of depressive symptoms in schizophrenia is still unclear, the results of Halari et al. (2006) suggest that they play an important role in the illness. However, because the authors claim that the investigation is the first to examine the role of subjective 
depression in schizophrenia, and few related investigations have been performed, further study of this relationship is necessary. Their results are theoretically consistent with repeated investigations revealing a relationship between depression or dysphoria and impaired neurocognitive functioning. Channon (1996) found that dysphoric college students did not perform as well as non-dysphoric college students on executive functioning tasks. Martin, Oren, and Boone (1991) found that patients with major depression and dysthymia did not perform as well on executive functioning tasks as healthy individuals; furthermore, depressed individuals' severity of symptoms was negatively correlated with performance of executive functioning tasks.

Strauss (2011) discusses the importance of the use of self-rated depression in the study by Halari et al. (2006). Strauss (2011) reflects upon the gap that exists between what clinicians believe that mentally ill patients are feeling and how patients actually feel. He explains that because our knowledge of severe psychopathology is collected from research and patients, and not from our own experience of severe mental illness, we cannot truly understand what they are experiencing unless it were to actually happen to us. Therefore, in future studies of the role affect in schizophrenia, it may be useful to contrast self-rated affect and clinician-rated affect to see if they yield the same results.

\section{The Relationship Between Affect and Thought Disorder in Schizophrenia}

While the literature examining the relationship between thought disorder and affect in psychotic illnesses is limited, findings suggest that affective disturbance is related to a greater severity of thought disorder. Jampala, Taylor, and Abrams (1985) found that manic patients who displayed emotional blunting were more severely thought disordered than manic patients who did not display emotional blunting and schizophrenic patients. Interestingly, blunted manic patients also experienced more classical schizophrenic symptoms than non-blunted manic 
patients. Jampala, Tayolor, and Abrams (1989) found that significantly more manic patients with thought disorder displayed lability of mood than manic patients without thought disorder and schizophrenic patients. Osher and Berdusky (2007) found that bipolar patients experiencing a normal, non-depressed mood displayed both more instances of thought disorder and a greater level of severity of thought disorder than healthy controls who were matched to the subject group average age and sex ratio as well as educational and cultural background. While these results do not directly examine the influence of affect on thought disorder, they suggest a relationship that should be investigated more thoroughly.

The limited research addressing affect and thought disorder provides a challenge for creating a theoretical framework causally linking the two, although the existing research (Jampala et al., 1985, 1989; Osher \& Berdusky, 2007) concerning psychiatric populations provides a foundation upon which to further explore it. Additionally, research in healthy populations also supports a relationship between affect and thinking. The existing evidence suggests that positive mood promotes greater efficiency and creativity in various cognitive processes. This appears to be a reciprocal relationship, as broad activation promotes positive affect. Negative affect, on the other hand, influences narrow processing, like that seen rumination. Rumination refers to "associations that surround a narrow focus" (Bar, 2009, p. 456), or focusing on one's feelings of distress.

There is some evidence that affect is related to symptomology. This point is introduced because positive and negative thought disorder are closely linked with other positive and negative symptoms. In a study by Koreen et al. (1993), first-episode schizophrenic patients experiencing acute psychosis-which is characterized by positive symptoms such as hallucinations, delusions, and positive thought disorder- concurrently experienced depressive 
symptoms. Throughout a five-year follow-up period, patients continued to experience depression concurrently with psychosis, with the depression remitting when the psychotic episodes subsided. While positive thought disorder is not necessarily a component of psychosis, their close relationship provides a reason to suspect that depressive symptoms may be related to positive thought disorder.

While depressive symptoms and positive symptoms differ greatly from one another, but can occur together (Andreasen \& Olsen, 1982), negative symptoms and depressive symptoms are more difficult to differentiate. The main negative symptoms in schizophrenia are affective flattening, alogia, avolition, and anhedonia, which are similar to some of the symptoms of depression. Both negative and depressive symptoms include a reduced amount of pleasure and psychomotor retardation (APA, 2000). Additionally, the negative symptom of affective flattening has a similar manifestation to a depressed mood, making them difficult to distinguish from one another. Rumination is a common feature of depression, leading to narrower, bottomup processing (Bar, 2009). Negative thought disorder includes the component of poverty of speech, or limited speech output (Andreasen, 1979a). It is possible that depressive symptoms in schizophrenia could contribute to negative thought disorder given that negative affect can lead to narrower thinking.

\section{The Relationship Between Thought Disorder and Neurocognitive Functioning in Schizophrenia}

There is some evidence that thought disorder may also be related to deficits in neurocognitive functioning, although the findings are inconclusive. While Owashi, Iwanami, Nakagome, and Higuchi (2009) found no significant relationship between thought disorder and executive functioning in schizophrenic patients, Nestor et al. (1998) found that thought disorder 
was significantly and negatively correlated with performance on an executive functioning and verbal memory tasks. However, the relationship between thought disorder and neurocognitive functioning has not been thoroughly investigated, and it warrants further study.

\section{Direction and Purpose of the Investigation}

The relationships between depressive symptoms and neurocognition in schizophrenia as examined in Halari et al. (2006); between affect and thought disorder as indirectly examined in Jamapala et al. (1985, 1989) and Osher and Berdusky (2007); and between thought disorder and neurocognitive functioning as examined by Owashi et al. (2009) and Nestor et al. (1998) have yet to be more firmly established. However, the implications of these findings suggest that these three variables share a complex relationship. If affect is a reliable predictor of impaired neurocognitive functioning, more instances of thought disorder, and a greater level of severity of thought disorder, perhaps effectively treating affective symptoms could improve neurocognitive functioning as well as decrease instances of and severity of thought disorder. However, much more research is needed is learn more about these intricate relationships.

In order to come closer to understanding the relationships between depressive symptoms and neurocognitive functioning and affect and thought disorder in schizophrenia, the current investigation includes two separate but closely related studies. The first study is an attempt to replicate the finding by Halari et al. (2006) that self-rated depression predicts neurocognitive functioning in the domains of attention, executive functioning, and verbal memory. The second study is an investigation of the relative contributions of self-rated and clinician-rated depression to both positive and negative thought disorder in schizophrenia. For the first study, it is predicted that the portion of the study by Halari et al. (2006) will be replicated. For the second study, it is 
predicted that self-rated depression will make a greater contribution than clinician-rated depression to both positive and negative thought disorder.

\section{Method}

\section{Participants}

The data used in this investigation were collected by Lewine, Haden, Caudle, and Shurret (1997). Details of patient recruitment can be read in their article. The sample taken by Lewine et al. (1997) consisted of over 600 patients, which includes individuals with a range of psychiatric disturbances as well as healthy comparison subjects. Of the original sample, 127 were diagnosed with schizophrenia using DSM-III-R criteria. The current study consists only of 27 schizophrenic individuals of the original sample who completed all of the measures relevant to this investigation. The Emory IRB approved the original study by Lewine et al. (1997). However, IRB approval for this investigation was not necessary because the data used was personally de-identified.

The average age of the patients in the sample is 40.4 years old, ranging from $25-79$ years old with a standard deviation of 13.7 years. There are 20 males (74.1\%) and seven females (25.9\%). Twenty-two of the patients are white $(81.5 \%)$, and five are black $(18.5 \%)$. The mean age at first hospitalization is 25.0 years old, ranging from 8-46 years old with a standard deviation of 8.8 years.

\section{Measures}

\section{Hamilton Depression Rating Scale (HDRS)}

The HDRS is a 21-item measure of clinician-rated depression. The clinician-rater uses a structured interview to gauge patients' feelings of depression over the past week. The questions inquire about depressive symptoms including depressed mood, guilt, and insomnia. Based on 
patients' answers, each item is scored on a likert scale scale of 0-4 in which 0 indicates an absence of the symptom and 4 indicates that the symptom is strongly present. The HDRS has an inter-rater reliability of 0.954 for patients whose primary diagnosis is not depression, according to a meta-analysis by Trajkovic et al. (2011).

Beck Depression Inventory (BDI)

The BDI is a 21-item measure of self-rated depression. In this study it is used to measure present feelings of depression rather than general feelings of depression. Patients are asked to rate negative feelings including sadness, sense of failure, and guilt on a likert scale from 0-3 in which 0 indicates the absence of negative feelings and 3 indicates a very strong presence of negative feelings. The BDI has been shown to have high test-retest reliability as well as high internal consistency reliability (McPherson \& Martin, 2010).

The Scale for the Assessment of Negative Symptoms (SANS): Alogia Subscale

The Alogia Subscale of the SANS was used to measure negative formal thought disorder. It consists of five items: poverty of speech, poverty of content of speech, blocking, increased latency of response, and a global rating of alogia. Poverty of speech and poverty of content are two types of negative formal thought disorder, and these two items are at the core of alogia. The entire Alogia Subscale was used because the scores for each individual item were unavailable. Inter-rater reliability of the SANS is best calculated through the use of intra-class correlation coefficients (ICC) between each item on the measure. In an investigation performed by Norman, Malla, Cortese, and Diaz (1996), the ICCs of the SANS ranged from 0.28 to 0.74 , with an average of 0.52 . Poverty of speech had an ICC of 0.63 , while poverty of content of speech had an ICC of 0.61 . 
The Scale for the Assessment of Positive Symptoms (SAPS): Positive Formal Thought Disorder Subscale

The Positive Formal Thought Disorder Subscale of the SAPS was used to measure positive formal thought disorder. It includes nine items: derailment, tangentiality, incoherence, illogicality, circumstantiality, pressure of speech, distractible speech, clanging, and a global rating of positive thought disorder. Like the SANS, inter-rater reliability of the SAPS is best calculated through the use of ICCs. Norman et al. (1996) found that the ICCs of the SAPS range from -0.01 to 0.91 , with an average of 0.52 . Derailment had an ICC of 0.72 , tangentiality had an ICC of 0.73 , incoherence had an ICC of 0.16 , illogicality had an ICC of 0.58 , circumstantiality had an ICC of 0.66 , pressure of speech had an ICC of 0.52 , distractible speech had an ICC of 0.44, clanging had an ICC of -0.01 , and the global rating of positive thought disorder had an ICC of 0.75

The Wisconsin Card Sorting Test (WCST)

The WCST was used to measure executive functioning. In this task, cards are sorted according to three criteria: color, number, or shape. The correct sorting criterion must be discovered without examiner assistance by the test taker. Once ten cards have been sorted correctly, the sorting criterion changes, and patients must once again discover the new sorting criterion by themselves. According to Laws (1999), the reliability of the WCST is questionable. Although it is the most commonly used measure to study executive functioning in schizophrenia patients, the methodology of many previous studies is unsuitable for pinpointing the precise nature of the cognitive deficit displayed by schizophrenia patients. While schizophrenics almost always perform more poorly than healthy controls, it is not clear exactly what is being measured. The Benton Controlled Oral Fluency Test (BCOF) 
The BCOF was used as a measure of verbal ability. In this task, patients have one minute to name as many words beginning with a specific letter that they can, not including numbers, proper nouns, or the same word with different suffixes. Impaired verbal fluency has been shown to be a good indicator of impaired frontal lobe functioning (Lezak, 1983).

\section{Wechsler Memory Scale-Revised (WMS-R) Immediate and Delayed Logical Memory Subscales}

The WMS-R Logical Memory Immediate and Delayed subscales were used as a measure of verbal memory. In this story memory task, the examiner reads two paragraphs to the patient. There are 24 memory units in the first paragraph, and there are 22 memory units in the second paragraph. The total score is the average number of ideas remembered from each paragraph. In the immediate task, the patient is asked to recall ideas from the two paragraphs immediately after hearing them. In the delayed task, the patient is asked to recall ideas from the two paragraphs after a delay of 20 minutes to an hour (Lezak, 1983). Abikoff et al. (1987) report an inter-rater reliability of greater than 0.99 for both the immediate and delayed subscales.

\section{Finger Tapping (FT)}

The FT was used as a measure of motor functioning. In this task, patients are required to tap their bent index finger against the thumb's second muscle; performance is usually better with the dominant hand. Movement occurs primarily in the index finger, although the thumb moves a small amount as well. Healthy individuals under the age of 50 should be able to tap at a rate of three to five times per second, and can perform slightly more quickly with the dominant hand (Fisher, 1960). There are five ten-second trials for each hand, and the average of these is taken as the score for each hand (Lezak, 1983).

Purdue Pegboard (PP) 
The PP was used as a measure of spatial motor functioning. In this task, patients are required to place pegs on a pegboard during three conditions lasting 30 seconds each: first with the left hand, then with the right hand, and finally, with both hands simultaneously. Each trial is scored separately, and the score is the number of correctly placed pegs (Lezak, 1983). The Dichotic Listening Task (DLT)

The DLT was used as a measure of attention. In this task, patients use headphones to listen to two distinct auditory stimuli, one presented to each ear. They are then asked to identify either one or both of the stimuli and they are asked about the content of one of the stimuli. The score is the total correct responses regarding what is heard in the right ear and the total correct responses regarding what is heard in the left ear.

Wechsler Adult Intelligence Scale-Revised (WAIS-R) Forward and Reverse Digit Span Subscales

The digit span subscale of the WAIS-R was used as a measure of verbal working memory. In the forward digit span, digits are read aloud to the patients at a rate of one digit per second. They are then asked to repeat increasing sequences of digits. The longest sequence of digits that is correctly recalled at least once is the span. In backward digit span, increasing sequences of digits are also read aloud, but patients are asked to repeat these sequences in the reverse order of their presentation. The backward digit span is one of the most commonly used measures of working memory in schizophrenia patients (Haatveit et al., 2010).

\section{Analyses}

Study 1

First, a bivariate correlation was performed to examine the relationship between patients' scores on the BDI and the HDRS. 
Multiple regression analyses were performed examining the contribution of self-rated depression to performance on neuropsychological tasks in an attempt to replicate the results of Halari et al. (2006) regarding the relationship between self-rated depression and neurocognitive functioning. The domains of neurocognitive functioning examined are executive functioning, verbal ability, verbal memory, motor functioning, spatial motor functioning, attention, and verbal working memory.

Study 2

Multiple regression analyses were performed to examine the contribution of both selfand clinician-rated depression, as measured by the BDI and the HDRS, to both negative and positive thought disorder.

\section{Results}

\section{Study 1}

Relationship Between Self- and Clinician-Rated Depression

Scores on the BDI and the HDRS were found to be weakly and negatively correlated ( $\mathrm{r}=$ -.088 , n.s.).

Depression and Neurocognitive Functioning

Patients' scores on the BDI did not predict performance on neurocognitive functioning tasks in any domain.

\section{Study 2: Depression and Thought Disorder}

Neither self- nor clinician-rated depression was found to predict the presence of negative thought disorder in schizophrenic patients. The full regression model, which included self- and clinician-rated depression, was not significant $(\mathrm{F}=.446 \mathrm{df}=2, p=.64)$. It was also found that 
neither self- nor clinician-rated depression predicted positive thought disorder. The full regression model was not significant $(\mathrm{F}=.906, \mathrm{df}=2, p=.42)$.

\section{Discussion}

This investigation included two studies: an attempted replication of Halari et al. (2006) and the search for a possible relationship between depression and positive and negative thought disorder in schizophrenia. The attempted replication of Halari et al. (2006) was unsuccessful. While they found a significant correlation between clinician-reported depression (measured by the Calgary Depression Scale [CDS] and the HDRS) and self-reported depression (measured by the Profile of Mood States [POMS]), the present study found a very weak, non-significant correlation between self- and clinician-reported depression (measured by the BDI and HDRS, respectively; $r=-0.088)$.

Halari et al. (2006) also found that greater levels of depression in schizophrenia predicted poor performance of neurocognitive functioning in several domains. They found that selfreported depression predicted performance on tasks of attention, executive functioning, and verbal memory, while clinician-rated depression predicted performance on a motor functioning task. Conversely, the present study found that depression, rated by the both the patient and clinician, did not predict performance on neurocognitive tasks in any domain.

The hypothesis of the second study was not realized. Neither self-reported nor clinicianreported depression was found to predict positive or negative thought disorder.

\section{Study 1}

Because the results by Halari et al. (2006) were not replicated, post-hoc Pearson listwise correlations were measured between both measures of depression and the neurocognitive tasks completed for the investigation to further examine the relationships between these variables. 
These correlations are presented in Table 2. Neither scores on the HDRS nor the BDI were significantly correlated with performance on any of the neurocognitive tasks.

\section{Measurement Differences}

One possible explanation of these incongruous results is a difference in measures between the study conducted by Halari et al. (2006) and the present study. Halari et al. (2006) used the depressed-dejected subscale of the POMS as a measure of self-reported depression while the BDI was used for the present investigation. The POMS is a self-report measure that asks participants to rate 72 mood-related adjectives on a five-point likert scale ranging from 0 ("not at all") to 4 ("extremely"). These adjectives are then grouped into six subscales: tensionanxiety, fatigue-inertia, depressed-dejected, anger-hostility, confusion, and vigor. Halari et al. (2006) report that the POMS has been used reliably for a variety of psychiatric patients. In contrast, the BDI is a 21-item questionnaire focusing only on depression and tends to measure symptoms.

In a recent study, Lako et al. (2012) reviewed depression scales commonly used for schizophrenia patients for reliability and validity. The BDI was the only self-report measure included in their analysis, and they found it to be reliable in measuring depressive symptoms in schizophrenia patients. However, they note that almost half of the items on this measure overlap with negative and extrapyramidal symptoms; these two types of symptoms are often difficult to distinguish in schizophrenia (Harvey, Koren, Reichenberg, \& Bowie, 2006; Lako et al., 2012). Despite this overlap, Lako et al. (2012) found the BDI to be a reliable measure of depression in schizophrenic patients.

The review by Lako et al. (2012) also included the HDRS, which was used in both the study by Halari et al. (2006) and the present study. They found the HDRS to be a reliable 
measure of depression within the schizophrenic population, with high levels of internal consistency (0.75), inter-rater reliability (0.94), and test-retest reliability $(0.75)$. Similarly to the BDI, however, more than half of the items in the HDRS also overlap with negative and extrapyramidal symptoms. Lako et al. (2012) report that the BDI and the HDRS have a moderate level of concurrent validity of 0.57 . Based on these findings, a stronger and positive correlation was expected between BDI and HDRS scores. The review by Lako et al. (2012) did not include the POMS.

In addition to the different self-report emotional scales used, there were also some differences in the neurocognitive tests used in each study, which are listed in Table 3. These differences are due to the available data. Because the data used for this study were originally collected for a different study (Lewine et al., 1997), the measures for each domain were not all the same as those used by Halari et al. (2006). However, the measures used were comparable. It should also be noted that the neurocognitive domains of speed of information processing and spatial memory were not measured in this study. They were omitted because a) Halari et al. (2006) found that neither of them was related to any subscale on the POMS, and b) no comparable measures were available from the data collected by Lewine et al. (1997).

In the study by Halari et al. (2006) and the present study, there were differences in the measures used in the following domains: verbal ability, spatial motor functioning, attention, and verbal working memory. In the domain of verbal ability, Halari et al. (2006) used phonological fluency and category fluency tasks, while the BCOF was used in the present investigation. However, in their article, an inadequate description of these tasks is provided. It is unclear whether these tasks are subscales of a larger test or whether they are individual measures. The 
procedure for this task is not described, nor is any measure of validity or reliability, so no conclusions can be made about these particular measures.

In the domain of spatial motor functioning, Halari et al. (2006) used the Grooved Pegboard task (GP) while the PP was used in the present investigation. In both tasks, the participant is required to place pegs inside holes on a pegboard. In the GP, there are 25 slotted holes arranged in a 5 X 5 square, and each is angled in a different direction (Lezak, 1983). In the $\mathrm{PP}$, there are 50 slots arranged into two vertical columns, each consisting of 25 slots (Strenge, Niederberger, \& Seelhorst, 2002). In both tasks, the patient is timed while inserting the pegs into the holes using both the dominant and non-dominant hand. In the PP, the participant is also tested using both hands together to insert the pegs (Lezak, 1983; Strenge et al., 2002).

In the domain of attention, Halari et al. (2006) used the Continuous Performance Test (CPT), D'Prime (d), Stroop Interference task, and Trails A, while this study used the DLT. The CPT is a computer-based test. Participants are asked to attend to the screen, where a stimulus is shown briefly. When participants see a specific target stimulus, they are supposed to press a lever or key. Failure to do so is called an omission error, while responding to a stimulus other than the target stimulus is called a commission error. Both acute and remitted schizophrenia patients show significant impaired performance on this task (Mussgay \& Hertwige, 1990; Wohlberg \& Kornetsky, 1973).

There are two types of performance measurements for the CPT: the number of correct responses (hits), which can also be inversely recorded by the number of incorrect responses (omissions), and the number of false alarms (commissions). The CPT can be scored using $d^{\prime} . d^{\prime}$ represents a net score: hits minus commissions. An individual who performs well on this task is one who maximizes hits and minimizes omissions. When an individual performs with 50\% 
accuracy on both hits and commissions, $d^{\prime}=0$. A negative score indicates that an individual has performed with less than $50 \%$ accuracy on both scores, whereas a positive score indicates that an individual performed with greater than $50 \%$ accuracy on both scores. Haatveit et al. (2010) report that the $d^{\prime}$ score is sensitive to performance between schizophrenic patients and healthy controls.

In the Stroop Interference task, participants read color words that are written in various colors of ink. Typically, response time is longer when a word is written in an incongruous color (for example, the word purple written in orange ink). In this task, reading the written word automatically interferes with the participant's ability to name the color in which it is written (Taylor, Kornblum, \& Tandon, 1996). The Stroop Interference task "appears to have a reasonable reliability and validity" (MacLeod, 1991, p. 166). In schizophrenia, a deficit in attention is believed to be a core feature of the illness. This would suggest that schizophrenic patients would experience a longer delay in naming the color of the ink than healthy controls. However, when used in schizophrenic populations, the Stroop Interference task has had mixed results. While some studies have reported that schizophrenic patients have a larger interference effect, others have not (Taylor et al., 1996).

In Trails A, participants are required to draw a line between consecutively numbered circles without lifting the pencil off of the paper as quickly as possible. While the Trails test is useful in distinguishing between brain damaged patients and healthy controls, it is inconsistent in differentiating between brain damaged and psychiatric patients (Lezak, 1983).

Despite the differences in measures used by Halari et al. (2006) and the current investigation, it was predicted that their findings would be replicated. Because both the BDI and the HDRS have been reliably used to measure depressive symptoms in schizophrenia, it was 
hypothesized that scores on these two measures would be more strongly correlated than the POMS and the HDRS. Additionally, it was expected that scores on the BDI would be a better predictor of neurocognitive performance than scores on the POMS for the same reason. However, as the neurocognitive measures used in both studies were either the same or comparable, it is unlikely, but not impossible, that using these different measures caused these incongruous results.

\section{Non-Replication in Psychology}

In addition to the measurement differences between the current investigation and that of Halari et al. (2006), the unsuccessful replication of the study by Halari et al. (2006) brings to light a much larger issue affecting the entire field of psychology: an alarming lack of the performance of replication studies. Nosek (2012) states that reproducibility, or repeating scientific studies and yielding the same results, is very important within the practice of science. Yet despite its significance, replication studies are rarely performed in present-day psychology. Nosek (2012) reports that in psychology, only one half of unpublished replication studies were successful in reproducing the original results.

While devoting too much time, energy, and money to replications can be a poor allocation of resources if the original results are valid, we may pay a high price in accepting false results. A few untrue findings will undoubtedly lead to the pursuit of new information based on this incorrect knowledge, and more resources will be wasted investigating ideas that are based in these erroneous results (Nosek, 2012). How long would we pursue these new leads before accepting defeat, when instead we could have attempted to replicate the original results and realized much sooner that they were false? 
The lack of replication in psychology has interesting implications for the present study. One possibility is that the results of the study by Halari et al. (2006) were false. As the authors are one of few teams to investigate the role of depression in schizophrenia, we cannot be completely sure that their results are correct. Additionally, the sample size was small (40 patients). If these findings are correct, perhaps they are valid only for this small group of patients, making the data non-generalizable. Regardless, it is important to attempt to replicate these findings.

\section{Study 2}

Neither self- nor clinician-rated depression was found to predict positive or negative thought disorder. One possible explanation for this result could be the measures used for positive and negative thought disorder. Positive thought disorder was measured using the Positive Formal Thought Disorder Subscale of the SAPS, and negative thought disorder was measured using the Alogia Subscale of the SANS. While eight of the nine items on the Positive Formal Thought Disorder subscale of the SAPS are types of positive thought disorder, the ninth being a global rating of positive thought disorder, only two of the five items on the Alogia subscale of the SANS are types of negative thought disorder: poverty of speech and poverty of content of speech. Two of the other items are not types of negative thought disorder, while the fifth is a global rating of alogia. Because scores for individual items were unavailable, the scores of the entire subscales of Positive Formal Thought Disorder and Alogia were used in the multiple regression analyses of thought disorder predicted by depression. While this would not have confounded the prediction of positive thought disorder, it will have confounded the prediction of negative thought disorder. 
A second possibility of why depression was not found to predict positive or negative thought disorder is simple: perhaps depressive symptoms are not a reliable predictor of thought disorder. Though the proposed model is based on findings suggesting a relationship between affect and thought disorder, the relationship between these two variables has not been directly examined, making it difficult to construct a hypothesis addressing a direct relationship between them.

It is also possible that depressive symptoms may be more likely to predict negative thought disorder than it is to predict positive thought disorder. Although depression has been linked to psychosis (Koreen et al., 1993), perhaps it is a reaction to the presence of positive symptoms rather than something that precedes them. In contrast, as negative affect has been shown to promote narrower thinking while positive affect has been shown to promote a heightened activation of semantic networks in healthy populations (Bar, 2009), the nature of depressive symptoms may be more likely to cause negative thought disorder than to occur as a reaction to negative thought disorder and other related negative symptoms. Although depression could be related to both negative and positive thought disorder, perhaps it is related to each one in a distinct manner.

\section{Future Research and Implications}

Due to the poorly understood nature of depressive symptoms in schizophrenia, it is important to explore this phenomenon in much greater depth. An additional replication of the study by Halari et al. (2006) is recommended, with several differences from the one conducted here. First, another replication should be carried out using the exact measures used by Halari et al. (2006). Second, a larger sample size is recommended. While the present investigation included 27 patients, and that conducted by Halari et al. (2006) included 40 patients, neither of 
these sample sizes provides the ideal statistical power. Third, it would be useful to include the BDI as well as the POMS to measure self-rated depression. Analyses examining the concurrent validity of these two measures and comparing their ability to predict performance on various neurocognitive functioning tasks would be useful in determining whether or not the POMS is as reliable of a measure as the BDI in evaluating depression in schizophrenia patients.

There is also a lot of work to be done investigation affect and thought disorder in schizophrenia. One suggestion for examination of thought disorder is to use a more comprehensive thought disorder measure than that the Positive Formal Thought Disorder Subscale of the SAPS and the Alogia Subscale of the SANS. A better measure of thought disorder for this work is the Thought Disorder Index (TDI; Johnston et al., 1986). The TDI is a much more comprehensive scoring system for thought disorder than the subscales of the SAPS and SANS. Not only does it include more specific types of thought disorder, it also includes a more standardized way of measuring thought disorder severity. While the subscales of the SAPS and the SANS are scored on a six-point likert scale from 0-5, the TDI groups each type of thought disorder into a specific level of severity of either $0.25,0.5,0.75$, or 1.0 . Though use of the TDI includes the administration of either the Rorschach test or the Wechsler Adult Intelligence Scale, takes extensive training to learn, and is time-consuming, it provides a very comprehensive assessment of thought disorder.

One disadvantage of the use of comprehensive measures such as the TDI is that it is difficult to provide standardized measurements of poverty of speech and poverty of content of speech. Although these concepts are not hard to understand, standardizing the level of severity of these types of thought disorder is complex given the need to consider total speech output versus ideas communicated. Additionally, it is important to use caution in measuring poverty of speech. 
Limited speech production may not reflect affected thought processes; it may be limited by mood in addition to disordered thinking.

A second suggestion for research examining affect and thought disorder is to examine the relationship directly, unlike earlier studies which only mention differences in type and severity of thought disorder between manic and schizophrenic patients and the absence or presence of emotional blunting. It would be useful to examine this relationship in schizophrenic patients, patients with other psychiatric illnesses, and healthy populations to see whether or not the relationships are the same or different in psychiatric and non-psychiatric groups.

A better understanding of the role of depression, and overall affect, in schizophrenia may be useful in treating the illness. If depression is found to contribute to impairments in neurocognitive functioning and thinking, then perhaps treating affective symptoms in addition to other symptoms could alleviate these impairments. While affective symptoms are not at the core of this illness (Andreasen, 1989), they appear to play an important role nonetheless.

An increased understanding of affect in schizophrenia may shift our understanding of the relationship between schizophrenia and psychotic affective conditions. Instead of being viewed as separate illnesses, maybe they should be considered as separate combinations of a spectrum of symptoms. This may be a more useful way of thinking of these illnesses, as they share other features including psychosis and thought disorder (Andreasen, 1979b). However, much more research is needed in this area to reach definite conclusions. 


\section{References}

Abikoff, H., Alvir, J., Hong, G., Sukoff, R., Orazio, J., Solomon, S., \& Saravay, S. (1987). Logical memory subtest of the Wechsler memory scale: Age and education norms and alternate-form reliability of two scoring systems. Journal of Clinical and Experimental Neuropsychology, 9, 435-448.

American Psychiatric Association. (2000). Diagnostic and statistical manual of mental disorders ( $4^{\text {th }}$ ed., text rev.). Washington, DC: American Psychiatric Association.

Andreasen, N. C. (1979a). Thought, language, and communication disorders. I. Clinical assessment, definition of terms, and evaluation of their reliability. Archives of General Psychiatry, 36, 1315-1321. Retrieved from http://archpsyc.jamanetwork. com.echo.louisville.edu/article.aspx?articleid $=492217$

Andreasen, N. C. (1979b). Thought, language and communication disorders. II. Diagnostic. significance. Archives of General Psychiatry, 36, 1315-1321.

Andreasen, N. C. (1982). Should the term "thought disorder" be revised? Comprehensive Psychiatry, 23, 291-299.

Andreasen, N. C. (1983). The Scale for the Assessment of Negative Symptoms. Iowa City, IA: University of Iowa College of Medicine.

Andreasen, N. C. (1984). The Scale for the Assessment of Positive Symptoms. Iowa City, IA: University of Iowa College of Medicine.

Andreasen, N. C. (1989). The American concept of schizophrenia. Schizophrenia Bulletin, 15, 519-531. Retrieved from http://schizophreniabulletin.oxfordjournals.org/

Bar, M. (2009). A cognitive neuroscience hypothesis of mood and depression. Trends in Cognitive Sciences, 13, 456-463. doi:10.1016/j.tics.2009.08.009 
Beck, A. T., Beamesderfer, A., \& Olivier-Martin, R. Assessment of Depression: The Depression Inventory. Oxford, England: S. Karger.

Buckley, P. F., Miller, B. J., Lehrer, D. S., \& Castle, D. J. (2009). Psychiatric comorbidities and schizophrenia. Schizophrenia Bulletin, 35, 383-402. doi:10.1093/schbul/sbn135

Channon, S. (1996). Executive function in depression: The Wisconsin Card Sorting Test. Journal of Affective Disorders, 107-114. Retrieved from http://www.sciencedirect.com/science/article/pii/0165032796000274

Elvevag, B., \& Goldberg, T. E. (2000). Cognitive impairment in schizophrenia is the core of the disorder. Critical Reviews in Neurobiology, 14, 1-21.

Fisher, C. M. (1960). A simple test of coordination in the fingers. Neurology, 10, 745-746.

Haatveit, B. C., Sundet K., Hugdahl, K., Ueland, T., Melle, I., \& Andreassen, O. A. (2010). The validity of $d$ prime as a working memory index: Results from the "Bergen $n$-back task.” Journal of Clinical and Experimental Neuropsychology, 32, 871-880. doi: 10.1080/13803391003596421

Halari, R., Mehrotra, R., Sharma, T., \& Kumari, V. (2006). Does self-perceived mood predict more variance in cognitive performance than clinician-rated symptoms in schizophrenia? Schizophrenia Bulletin, 32, 751-757. doi: 10.1093/schbul/ sbl002

Hamilton, M. (1967). Development of a rating scale for primary depressive illness. British Journal of Social and Clinical Psychology, 6, 278-296.

Harvey, P. D., Koren, D., Reichenberg, A., \& Bowie, C. R. (2006). Negative symptoms and Cognitive deficits: What is the nature of their relationship? Schizophrenia Bulletin I, 
32, 250-258. doi: 10.1093/schbul/sbj011

Johnston, M. H., Holzman, P. S., Solovay, M. R., Shenton, M. E., Gasperetti, C., Coleman, M., Kastnbaum, E., \& Carpenter, J. T. (1986). Scoring manual for the Thought Disorder Index. Schizophrenia Bulletin, 12, 483-496. Retrieved from http://schizophreniabulletin. oxfordjournals.org/content/12/3/483.full.pdf + html

Koreen, A. R., Siris, S. G., Chakos, M., Alvir, J., Mayerhoff, D., \& Lieberman, J. (1993). Depression in first-episode schizophrenia. The American Journal of Psychiatry, 150, 1643-1648.

Kring, A. M. \& Caponigro, J. M. (2010). Emotion in schizophrenia: Where feeling meets thinking. Current Directions in Psychological Science, 19, 255-259. doi: $10.1177 / 0963721410377599$

Lako, I. M., Bruggeman, R., Knegtering, H., Wiersma, D., Schoevers, R. A., Slooff, C. J., \& Takis, K. (2012) A systematic review of instruments to measure depressive symptoms in patients with schizophrenia. Journal of Affective Disorders, 140, 38-47. doi: 10.1016/j.jad.2011.10.014

Laws, K. R. (1999). A meta-analytic review of Wisconsin Card Sort studies in schizophrenia: General intellectual deficit in disguise? Cognitive Neuropsychiatry, 4, 1-35. Retrieved From http://web.ebscohost.com/ehost/pdfviewer/pdfviewer?sid=38b2222d-2531-48ce87c4-240d656ae466\%40sessionmgr12\&vid=2\&hid=18

Lewine, R., Haden, C., Caudle, J., \& Shurett, R. Sex-onset effects on neuropsychological function in schizophrenia. Schizophrenia Bulletin, 23, 51-61. Retrieved from http://schizophreniabulletin.oxfordjournals.org/ content/23/1/51.full.pdf + html 
Lezak, M. D. (1983). Neuropsychological Assessment. (2 ${ }^{\text {nd }}$ ed.). Oxford: Oxford University Press.

Levy, D. L., Coleman, M. J., Heejong, S., Ji, F., Matthysse, S., Mendell, N. R., \& Titone, D. (2010). The genetic basis of thought disorder and language and communication disturbances in schizophrenia. Journal or Neurolinguistics, 23, 176-192. doi: 10.1016/j.jneuroling.2009.08.003

MacLeod, C. M. (1991). Half a century of research on the Stroop effect: An integrative review. Psychological Bulletin, 109, 163-203. Retrieved from http:/ovidsp.tx.ovid.com/

Martin, D. J., Oren, Z., \& Boone, K. (1991). Major depressives’ and dysthymics’ performance on the Wisconsin Card Sorting Test. Journal of Clinical Psychology, 47, 684-690. Retrieved from http://web.ebscohost.com.echo.louisville.edu/

McPherson, A. \& Martin, C. R. (2010). A narrative review of the Beck Depression Inventory (BDI) and implications for its use in an alcohol-dependent population. Journal of Psychiatric and Mental Health Nursing, 17, 19-30. doi: 10.1111/j.13652850.2009.01469.x

Mussgay, L. \& Hertwig, R. (1990). Signal detection indices in schizophrenics on a visual, Auditory, and bimodal Continuous Performance Test. Schizophrenia Research, 3, 303-310. Abstract retrieved from http://uofl.worldcat.org.echo.louisville.edu.

National Institute of Mental Health. (2009). Schizophrenia. Retrieved on November 5, 2012, from http://www.nimh.nih.gov/health/publications/schizophrenia/complete-index.shtml.

Nestor, P.G., Shenton, M.E., Wible, C., Hokama, H., O’Donnell, B.F., Law, S., \& McCarley, R. W. (1998). A neuropsychological analysis of schizophrenic thought disorder. Schizophrenia Research, 29, 217-225. Retrieved from http://www.sciencedirect.com/ 
science/article/pii/S0920996497001011

Norman, R. M. G., Malla, K. M., Cortese, L., \& Diaz, F. (1996). A study of the interrater reliability of the SAPS, SANS, and PANSS. Schizophrenia Research, 19, 73-85.

Nosek, B. A. (2012). An open, large-scale, collaborative effort to estimate the reproducibility of psychological science. Perspectives on Psychology, 7, 657-660. doi:

$$
10.1177 / 1745691612462588
$$

Owashi, T., Iwanami, A., Nakagome, K., Higuchi, T., \& Kamijima, K. (2009). Thought disorder and executive dysfunction in patients with schizophrenia. International Journal of Neuroscience, 119, 105-123. doi: 10.1080/00207450802324127

Strauss, J. (2011). Subjectivity and severe psychiatric disorders. Schizophrenia Bulletin, 37, 8-13. doi: 10.1093/schbul/sbq116

Strenge, H., Niederberger, U., \& Seelhorst, U. (2002). Correlation between tests of attention and performance on Grooved and Purdue Pegboards in normal subjects. Perceptual and Motor Skills, 95, 507-514. Retrieved from http://www.amsciepub.com/toc/pms/95/2

Taylor, S. F., Kornblum. S., \& Tandon, R. (1996). Facilitation and interference of selective attention in schizophrenia. Journal of Psychiatric Research, 30, 251-259. Retrieved from http://www.sciencedirect.com/science/article/pii/0022395695000461

Trajkovic, G., Starcevic, V., Lestarevic, M., Ille, T., Bukumiric, Z., \& Marinkovic, J. (2011). Reliability of the Hamilton Rating Scale for Depression: A meta-analysis of 49 years. Psychiatry Research, 189, 1-9. doi 10.1016/j.psychres.2010.12.007

Van Os, J. \& Kapur, S. (2009). Schizophrenia. Lancet, 374, 635-645. Retrieved from http://search.proquest.com/docview/199047908?accountid=14665

Wechsler, D. (1987). Wechsler Memory Scale_-Revised. New York, NY: Psychological 


\section{Corporation.}

Wohlberg, G. W. \& Kornetsky, C. (1973) Sustained attention in remitted schizophrenics. Archives of General Psychiatry, 28, 533-537. Retrieved from http://archpsyc. jamanetwork.com/journal.aspx 
Table 1

Subtypes of Thought Disorder*

\begin{tabular}{|c|c|c|}
\hline Subtype & Explanation & Example \\
\hline Derailment & $\begin{array}{l}\text { During speech, ideas slip off } \\
\text { track to another one that is } \\
\text { obliquely related or completely } \\
\text { unrelated. }\end{array}$ & $\begin{array}{l}\text { Interviewer: "What did you think of } \\
\text { the whole Watergate affair?" } \\
\text { Patient: "You know I didn't tune in in } \\
\text { that, I felt so bad about it. I said, boy, } \\
\text { I'm not going to know what's going on } \\
\text { in this. But it seemed to get murky, } \\
\text { and everyone's results were so } \\
\text { negative. Huh, I thought, I don't want } \\
\text { any part of this, and I was I don't care } \\
\text { who was in on it, and all I could figure } \\
\text { out was Artie had something to do } \\
\text { with it." }\end{array}$ \\
\hline Tangentiality & $\begin{array}{l}\text { Replying to a question in an } \\
\text { oblique, tangential, or irrelevant } \\
\text { manner. }\end{array}$ & $\begin{array}{l}\text { Interviewer: "What city are you } \\
\text { from?" } \\
\text { Patient: "Well that's a hard question to } \\
\text { answer because my parents...I was } \\
\text { born in Iowa, but I know that I'm } \\
\text { white instead of black so apparently I } \\
\text { came from the North somewhere..." }\end{array}$ \\
\hline Incoherence & $\begin{array}{l}\text { Speech is incomprehensible. } \\
\text { May be due to disregard for } \\
\text { syntactical and grammatical } \\
\text { rules, joining portions of } \\
\text { coherent sentences together into } \\
\text { an incoherent whole, incorrect } \\
\text { word usage, omission of } \\
\text { conjunctions and adjectival } \\
\text { pronouns. Often accompanied } \\
\text { by derailment. }\end{array}$ & $\begin{array}{l}\text { Interviewer: "Why do you think } \\
\text { people believe in God?" } \\
\text { Patient: "Um, because making a do in } \\
\text { life. Isn't none of that stiff about } \\
\text { evolution guiding isn't true anymore. } \\
\text { It all happened a long time ago. It } \\
\text { happened in eons and eons and stuff } \\
\text { and they won't believe in him. The } \\
\text { time that Jesus Christ people believe in } \\
\text { their thing people believed in, Jehovah } \\
\text { God that they didn't believe in Jesus } \\
\text { Christ that much." }\end{array}$ \\
\hline Illogicality & $\begin{array}{l}\text { Speaker reaches conclusions } \\
\text { that do not follow logically. } \\
\text { May manifest as nonsequitors } \\
\text { or reaching conclusions based } \\
\text { on incorrect premises without } \\
\text { the presence of delusional } \\
\text { thinking. }\end{array}$ & $\begin{array}{l}\text { "Parents are the people that raise you. } \\
\text { Any thing that raises you can be a } \\
\text { parent. Parents can be anything, } \\
\text { material, vegetable, or mineral, that } \\
\text { has taught you something. Parents } \\
\text { would be the world of things that are } \\
\text { alive, that are there. Rock, a person } \\
\text { can look at a rock and learn something } \\
\text { from it, so that would be a parent." }\end{array}$ \\
\hline
\end{tabular}




\begin{tabular}{|c|c|c|}
\hline & $\begin{array}{l}\text { indifferent in reaching its goal } \\
\text { idea. Speaker often needs to be } \\
\text { interrupted and urged to get to } \\
\text { the point. Often described as } \\
\text { long-winded. }\end{array}$ & \\
\hline Pressure of speech & $\begin{array}{l}\text { Amount of speech produced is } \\
\text { more than what is considered to } \\
\text { be normal; patient speaks } \\
\text { rapidly and is difficult to } \\
\text { interrupt. Quantitatively } \\
\text { described as greater than } 150 \\
\text { words per minute. }\end{array}$ & \\
\hline Distractible speech & $\begin{array}{l}\text { Patient is easily distracted } \\
\text { during speaking by other } \\
\text { irrelevant stimuli. }\end{array}$ & $\begin{array}{l}\text { "Then I left San Francisco and moved } \\
\text { to... where did you get that tie? It looks } \\
\text { like it's left over from the " } 50 \text { s." }\end{array}$ \\
\hline Clanging & $\begin{array}{l}\text { Word choice is governed by } \\
\text { sounds rather than meaningful } \\
\text { relationships. }\end{array}$ & $\begin{array}{l}\text { "I'm not trying to make noise. I'm } \\
\text { trying to make sense. If you can make } \\
\text { sense out of nonsense, well, have fun. } \\
\text { I'm trying to make sense out of sense. } \\
\text { I'm not making sense (cents) anymore. } \\
\text { I have to make dollars." }\end{array}$ \\
\hline Poverty of speech & $\begin{array}{l}\text { Amount of speech is restricted; } \\
\text { questions are answered without } \\
\text { elaboration. }\end{array}$ & $\begin{array}{l}\text { Interviewer: "How many children do } \\
\text { you have?" } \\
\text { Patient: "Two." }\end{array}$ \\
\hline $\begin{array}{l}\text { Poverty of content of } \\
\text { speech }\end{array}$ & $\begin{array}{l}\text { Amount of speech is adequate, } \\
\text { but little information is } \\
\text { conveyed }\end{array}$ & $\begin{array}{l}\text { Interviewer: Tell me what you are like, } \\
\text { what kind of person you are." } \\
\text { Patient: "Ah one hell of an odd thing } \\
\text { to say perhaps in these particular } \\
\text { circumstances, I happen to be quite } \\
\text { pleased who I am or how I am and } \\
\text { many of the problems that I have and } \\
\text { have been working on I have are } \\
\text { difficult for me to handle..." }\end{array}$ \\
\hline
\end{tabular}

*Adapted from Andreasen (1979a) 
Table 2

Pearson Listwise Correlations Between Depression Measures and Neurocognitive Tasks

\begin{tabular}{lll}
\hline & HDRS & BDI \\
\hline BCOF & -.048 & -.195 \\
WMS-R LM 1 & .018 & -.243 \\
WMS-R LM 2 & -.038 & -.258 \\
FT: Right & -.013 & -.211 \\
FT: Left & -.071 & -.205 \\
PP: Right & -.044 & -.063 \\
PP: Left & -.121 & -.008 \\
WCST Errors & -.128 & .335 \\
WCST Categories & .204 & -.293 \\
Completed & & \\
WCST Perseverative & -.159 & .299 \\
Responses & & \\
DLT: Total Correct Right & -.305 & -.131 \\
DLT: Total Correct Left & .052 & -.115 \\
WAIS: Digit Span Forward & -.084 & -.247 \\
WAIS: Digit Span & .060 & -.274 \\
Backward & & \\
\hline
\end{tabular}

Table 3

Neurocognitive Measures Used in Halari et al. (2006) and the Current Investigation

\begin{tabular}{lll}
\hline Neurocognitive Domain & Halari et al. (2006) & Present Investigation \\
\hline Executive functioning & WCST, Trails B & WCST \\
\hline Verbal ability & $\begin{array}{l}\text { Phonological Fluency, } \\
\text { Category Fluency }\end{array}$ & BCOF \\
\hline Verbal memory & $\begin{array}{l}\text { Logical Memory } \\
\text { (immediate and delayed), } \\
\text { Bushke Selective } \\
\text { Reminding Test (BSRT) }\end{array}$ & $\begin{array}{l}\text { Logical Memory } \\
\text { (immediate and delayed) }\end{array}$ \\
\hline Motor functioning & FT & FT \\
\hline Spatial motor functioning & GP & PP \\
\hline Attention & $\begin{array}{l}\text { CPT, D'Prime, Stroop } \\
\text { Interference, Trails A }\end{array}$ & DLT \\
\hline Verbal working memory & Letter Number & $\begin{array}{l}\text { Digit Span (forward and } \\
\text { backward) }\end{array}$ \\
\hline $\begin{array}{l}\text { Speed of information } \\
\text { processingVerbal }\end{array}$ & $\begin{array}{l}\text { Speed of Comprehension } \\
\text { Test }\end{array}$ & none \\
\hline Spatial memory & $\begin{array}{l}\text { Benton Visual Retention } \\
\text { Test (BVRT) }\end{array}$ & none \\
\hline
\end{tabular}

